2003-01-2636

\title{
An On-line Technology Information System (OTIS) for Advanced Life Support
}

\author{
Julie A. Levri \\ NASA Ames Research Center \\ Richard Boulanger \\ Sverdrup Technology \\ John A. Hogan \\ Rutgers, the State University of New Jersey \\ Luis Rodriguez \\ National Research Council
}

Copyright @ 2003 SAE International

\begin{abstract}
An On-line Technology Information System (OTIS) is currently being developed for the Advanced Life Support (ALS) Program. This paper describes the preliminary development of OTIS, which is a system designed to provide centralized collection and organization of technology information.
\end{abstract}

The lack of thorough, reliable and easily understood technology information is a major obstacle in effective assessment of technology development progress, trade studies, metric calculations, and technology selection for integrated testing. OTIS will provide a formalized, wellorganized protocol to communicate thorough, accurate, current and relevant technology information between the hands-on technology developer and the ALS Community.

The need for this type of information transfer system within the Solid Waste Management (SWM) element was recently identified and addressed. A SWM Technology information Form (TIF) was developed specifically for collecting detailed technology information in the area of SWM. In the TIF, information is requested from SWM technology developers, based upon the Technology Readiness Level (TRL). Basic information is requested for low-TRL technologies, and more detailed information is requested as the TRL of the technology increases. A comparable form is also being developed for the wastewater processing element. In the future, similar forms will also be developed for the ALS elements of air revitalization, food processing, biomass production and thermal control. These ALS element-specific forms will be implemented in OTIS via a web-accessible interface, with the data stored in an object-oriented relational database (created in MySQL ${ }^{\mathrm{TM}}$ ) located on a secure server at NASA Ames Research Center.

With OTIS, ALS element leads and managers will be able to carry out informed research and development investment, thereby promoting technology through the TRL scale. OTIS will also allow analysts to make accurate evaluations of technology options. Additionally, the range and specificity of information solicited will help educate technology developers of programmatic needs.

\section{INTRODUCTION AND BACKGROUND}

Currently, there are no formalized protocols to communicate technology characteristics and development progress between the ALS researcher/technology developer and the ALS Community (analysts, managers, researchers, etc.). This lack of reliable, comparable and easily understood technology information is a major obstacle in effective assessment of technology development progress, trade/system studies, metric calculations, and technology selection for integrated testing. Therefore, an organized, efficient means of capturing and conveying technology attributes and status information directly from the technology developer is an urgent need in the ALS Program.

The ALS OTIS will enable centralized collection and organization of technology characteristics to improve the quality of decision-making in the ALS Program through enhanced technology understanding and information sharing. OTIS will make detailed information of 
technology capabilities and limitations readily accessible by the ALS Community. Such characterization is necessary to determine the ability to satisfy requirements for space missions and ground-based test beds, and to pinpoint areas in need of further research and technology development (R\&TD). This "living" database will address the ALS elements of solid waste, air revitalization, water recovery, food processing, biomass production and thermal control.

Because technology development may occur through multiple, simultaneous projects, technology information within OTIS will be collected and organized by each distinct project. Consider the example in which one researcher develops a primary hardware unit, and another researcher develops a pre-processing device for that primary hardware unit. Both principal investigators of those projects will complete technology information forms for the respective projects, and those TIF's will be linked to establish the relationship between projects.

Existing NASA technology and/or project databases (OBPR, Tech-net, and SBIR) consist mostly of general information, such as abstracts, principal investigator (PI) contact information and project administration information. The degree of detail in the information contained within OTIS will allow for more detailed data mining of technology characteristics as well as the classical general information.

OTIS will provide thorough, accurate, current and relevant information to the ALS Community. The database will contain more detailed, descriptive information than a traditional, numerically oriented database. Technology developers will be given the opportunity to explain all information that is entered into the database by including textual commentary. Technology information will likely be updated on an annual basis. Such precautions allow for collection of thorough, accurate, current information.

By asking the ALS Community for critiques and through preliminary testing of OTIS, information is more likely to be of relevance to ALS needs. In this respect, it is expected that OTIS will provide most of the ALS Community with a large portion of the desired technology information and will serve as an initial point for literature searches. Additionally, OTIS will provide contact information for technology developers, so that any information that is not adequately addressed in OTIS can be clarified via direct communication with the technology developer. OTIS will also be continually improved as helpful suggestions from the ALS Community are solicited and incorporated.

\section{TECHNOLOGY INFORMATION FORMS}

\section{SOLID WASTE MANAGEMENT TECHNOLOGY INFORMATION FORM}

The need for an information transfer system within the Solid Waste Management element was recently identified and addressed. A SWM TIF was developed specifically for collecting detailed technology information in the area of SWM (Levri et al., 2001; Alazraki et al., 2002; Hogan et al. 2002; Levri et al., 2002). The TIF was created over a period of six months ${ }^{1}$ with assistance from the ALS SWM Working Group (consisting of technology developers, managers, and analysts). In the TIF, specific information is requested from SWM technology developers based upon the technology's current TRL. Basic information is requested for low-TRL technologies, and more detailed information is requested as the TRL of the technology increases.

In the SWM TIF, information is requested in the categories presented in Tables 1 through 4 . Please note that the informational requests in Tables 1 through 4 have been paraphrased from the actual SWM TIF, in the interest of document length. The tables describe the types of informational requests that will be made to SWM technology developers that use OTIS. The informational categories are 1) functional performance, 2) safety, 3) cost, and 4) historical and programmatic.

The "TRL" column indicates the level of technology development that is expected to be necessary in order to provide the requested information. The values denote the lowest TRL at which that particular information is requested. For example, if the TRL of a request is 2 , then information should be reported for that request for all technologies that are at a TRL of 2 or greater. However, users will not be deterred from answering questions with TRL assignments that are greater than the TRL of the technology of interest. TRL's were assigned to individual informational requests according to the expertise of the SWM Working Group. However, as OTIS is initiated and tested, the TRL assignments may change as seen suitable by other technology developers, ALS Management and the OTIS development team.

\footnotetext{
${ }^{1}$ Actually, six months were required for organization of concepts, and six additional months were required for development and critique of form content.
} 
Table 1 Functional Performance Information Requested in the SWM TIF

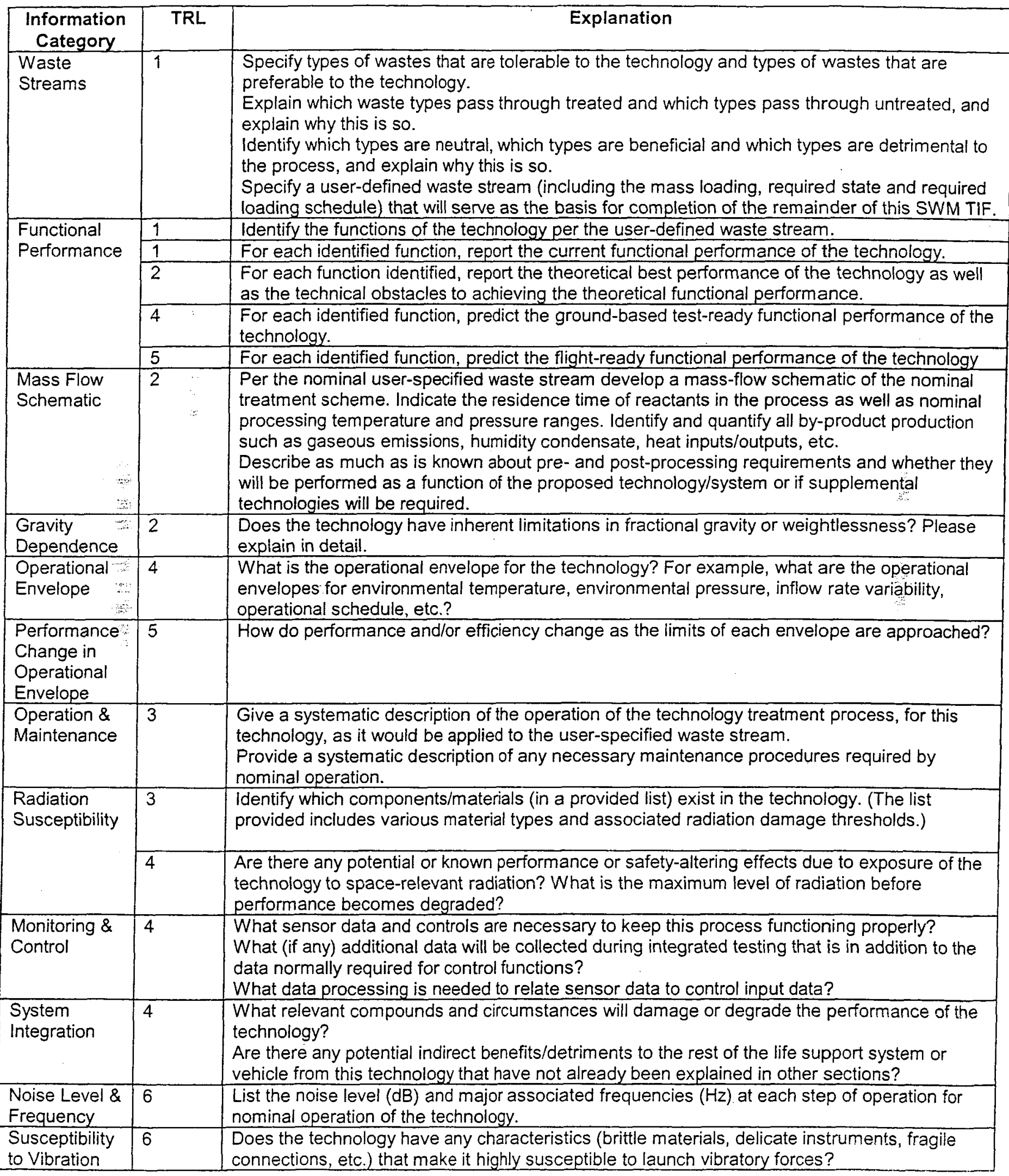


Table 2 Safety Information Requested in the SWM TIF

\begin{tabular}{|l|l|l|}
\hline $\begin{array}{c}\text { Information } \\
\text { Category }\end{array}$ & TRL & \\
\hline $\begin{array}{l}\text { Hazard } \\
\text { Identification }\end{array}$ & 1 & $\begin{array}{l}\text { Identify and quantify (when possible) all hazards present during nominal operation of the } \\
\text { technology. } \\
\text { For each listed hazard, describe safety features currently incorporated or to be incorporated } \\
\text { into the system design to control the hazard. } \\
\text { For each hazard of the technology, is it expected that the hazard will be lessened or eliminated } \\
\text { by further research and technology development? }\end{array}$ \\
\hline $\begin{array}{l}\text { Failures and } \\
\text { Controls }\end{array}$ & 3 & $\begin{array}{l}\text { In a list format, predict possible or report known off-nominal events/failures in operation of the } \\
\text { technology. When relevant, propose controls for prevention of each event/failure. }\end{array}$ \\
\hline $\begin{array}{l}\text { Reliability and } \\
\text { Life Testing }\end{array}$ & 4 & $\begin{array}{l}\text { Please report the estimated reliability (probability of operating without malfunction) for the time } \\
\text { sufficient to complete the performance testing. Describe the life testing and analysis used to } \\
\text { establish this reliability. }\end{array}$ \\
\hline
\end{tabular}

Table 3 Cost Information Requested in the SWM TIF

\begin{tabular}{|c|c|c|}
\hline $\begin{array}{c}\text { Information } \\
\text { Category }\end{array}$ & TRL & Explanation \\
\hline \multirow[t]{5}{*}{$\begin{array}{l}\text { Mass, } \\
\text { Volume, } \\
\text { Power, } \\
\text { Cooling, } \\
\text { Crewtime }\end{array}$} & & $\begin{array}{l}\text { Per the mass flow schematic, estimate the equipment mass, resupply mass, resupply volume, } \\
\text { equipment volume, nominal power, } 24 \text {-hr average power and peak power, nominal cooling, } \\
24-\mathrm{hr} \text { average cooling, peak cooling, and crew time. Include resources for operation and } \\
\text { maintenance during nominal operation. Include and explain any necessary free space around } \\
\text { the equipment for crew access, safety purposes or other purposes. Please explain values as } \\
\text { well as their uncertainty/variance in as much detail as possible. }\end{array}$ \\
\hline & 2 & - Theoretical Values \\
\hline & 3 & - Current Values \\
\hline & 4 & - Ground-Based Test-Ready Values \\
\hline & 5 & - Flight-Ready Values \\
\hline $\begin{array}{l}\text { Scaling } \\
\text { Factors }\end{array}$ & 3 & $\begin{array}{l}\text { Indicate scaling factors for each hardware component of the technology for mass, volume, } \\
\text { power, cooling and crewtime. Scaling factors should indicate scaling from a current hardware } \\
\text { prototype flowrate to the user-specified waste stream flowrate or to that appropriate for a } 6 \text { - } \\
\text { person crew. }\end{array}$ \\
\hline $\begin{array}{l}\text { Research and } \\
\text { Development } \\
\text { Costs }\end{array}$ & 2 & $\begin{array}{l}\text { If the current TRL is less than } 5 \text {, estimate the overall cost required to bring the technology } \\
\text { through a TRL of } 5 \text {, indicating it has gone through successful integrated subsystem testing. } \\
\text { What unresolved technical issues are hindering the advancement of this technology from the } \\
\text { current TRL through TRL } 5 \text { (or through the next TRL if the current TRL is } 5 \text { or greater)? } \\
\text { Which of these research issues are "cross-cutting", meaning that they will benefit other space } \\
\text { flight-related technologies as well as this one, if resolved? If it is claimed that a research issue } \\
\text { is "cross-cutting", specify which other technologies would benefit from resolution of the issue. }\end{array}$ \\
\hline
\end{tabular}

Table 4 Programmatic and Historical Information in the SWM TIF

\begin{tabular}{|c|c|c|}
\hline $\begin{array}{l}\text { Information } \\
\text { Category }\end{array}$ & TRL & Explanation \\
\hline $\begin{array}{l}\text { Development } \\
\text { and Funding } \\
\text { History, \& } \\
\text { Key } \\
\text { References }\end{array}$ & 1 & $\begin{array}{l}\text { Describe, as thoroughly as possible, the development and funding history of the technology for } \\
\text { this specific R\&TD effort. } \\
\text { Provide a listing of any key publications and presentations that have resulted from this } \\
\text { research/technology development on this technology }\end{array}$ \\
\hline $\begin{array}{l}\text { Mission } \\
\text { Applicability }\end{array}$ & 3 & $\begin{array}{l}\text { Discuss the applicability (if any) of the technology to the missions described in the ALS } \\
\text { Reference Missions Document. }\end{array}$ \\
\hline
\end{tabular}


OTHER ALS ELEMENT TECHNOLOGY INFORMATION FORMS

Building upon the knowledge gained from development of the SWM TIF, analogous forms will be customized for the other five major ALS elements: air revitalization, wastewater processing, food processing, biomass production and thermal control. Much of the information requested in the SWM TIF will be applicable to the other ALS elements. However, it is anticipated that additional types of information will be required for each distinct ALS element. As technology information forms are developed for each ALS element, newly gained information from successive efforts will provide valuable feedback to previous element TIF's.

While creating the SWM TIF, it was realized that group critique during form development is essential for a coherent and quality product. Therefore, similar working groups will be established within each ALS element to critique content and organization of the forms during development. In addition to OTIS development team members, each working group will consist of the specific ALS Element Lead and other volunteers within the ALS Community (researchers, managers, administrators, technology developers, and system analysts) that have experience in the ALS element of focus. Each working group will conduct biweekly teleconferences for approximately six months to discuss TIF contents to guarantee that the forms request the most appropriate information from technology developers for that specific ALS area.

Group development of future TIF's will be initiated by introducing the working group to the existing SWM TIF. It is anticipated that introduction to a "starting" document will trigger discussion on the types of information that must be collected in order to capture the technology traits in the ALS element of focus. Based on experience with the SWM TIF, modifications to the form will be made after each teleconference, and the revised form will be distributed to the working group a few days before the follow-up meeting. In taking such an approach with the SWM TIF, it was found that approximately six months of discussion and form revision were necessary to develop a thorough, cogent form. After the six-month development period within the working group, the form will be presented to the ALS Community for further critique at an ALS Technical Interchange Meeting.

\section{DATABASE AND INTERFACE DEVELOPMENT AND TESTING}

The OTIS database and interface are currently being developed at NASA Ames Research Center. OTIS will be web-accessible through dynamically created HTML forms, with the data stored in an object-oriented relational database located on a secure server located at NASA Ames Research Center. The database will be implemented in MYSQL (MYSQL AB, Seattle, WA). The
MySQL database software package was chosen for its versatility, reliability and affordability.

The server for OTIS is online and accessible to the public (http://www.otis.arc.nasa.gov) and database schema are currently being developed for access, contact, permissions and technology data in MySQL. PHP Hypertext Preprocessor is applied in Adobe ${ }^{\circledR}$ GoLive $\circledast$ in conjunction with MySQL to generate dynamic web pages that provide forms for the requisite information from the user.

Access privileges for OTIS will consist of "Write" access and various levels of "Read" access. Read accessibility will be designed so that Pl's can designate certain data as proprietary and protect it as such. Read accessibility will be designed in a robust, scalable manner such that only specified users can access proprietary information for specific projects. Similarly, Write accessibility will be designed such that specified users can write information to specific projects. The PI will be able to grant Write access to specific registered users, such as contractors or graduate assistants, in order to facilitate TIF completion. However, only the PI will have the ability to submit the final TIF to be uploaded to the OTIS database.

Upon implementation by ALS Management, TIF's within OTIS might be updated on an annual -fiscal year schedule) basis, for as long as project funding continues. Yearly submissions of TIF's will be tracked within OTIS to allow ALS Managers to trace the R\&TD progress of a particular technology or a particular project. As the TRL of a technology advances, increasingly detailed information will be requested from the PI for the OTIS database. Such implementation may also facilitate the use of annual OTIS TIF updating to replace year-end research reports. In the near future, OTIS may also be expanded to management of all ALS projects, rather than just projects that involve hardware development.

As the TIF's for each ALS element and the OTIS database are developed, tested, revised and populated, the possibility of automated post-collection data analysis will be evaluated in accordance with usefulness to the ALS Community. Post-collection data analyses can create value-added information, based on existing information in the database. However, technology data is often collected relative to specific implementation scenarios, such as specified mission environments. It is anticipated that this could make automated data analyses a complex task. However, if useful and accurate analyses can be identified, the ability of OTIS to provide valuable information increases, increasing the utility of the platform. After the database has accumulated several years of historical data, relationships between feasible analyses may emerge. For example, we may begin to see such things as a relationship between financial investment in a project versus TRL. 
At least three, current technology developers within each ALS area will be solicited, with appropriate monetary compensation, to test OTIS by completing TIF's for a particular technology using the on-line interface. At least two of the testing participants will not be involved with the specific element working group in order to guarantee objective evaluation of overall system accuracy and "user-friendliness". By completing the form, as opposed to merely reading and evaluating the form, true testing will be achieved. Allowing technology developers to test the form and electronic interface before they are released to the Community provides valuable feedback that will ensure successful implementation. Simultaneously, completion of on-line forms in each ALS element initiates construction of the database contents.

\section{CONCLUSIONS}

The OTIS product will be a thoroughly tested, on-line technology information system, with forms specifically designed for capturing thorough, accurate, current and relevant technology information within each ALS element. Upon successful demonstration of the value of OTIS, ALS management may choose to adopt OTIS as a means of tracking and analyzing R\&TD activity. Thus, researchers and technology developers may be required to complete/update database entries on an annual basis.

\section{ACKNOWLEDGMENTS}

This work was funded partially by the New Jersey EcoComplex Life Support Center, partially by NASA ALS Technology Development funds, and partially by the National Research Council. The authors would also like to thank the members of the ALS SWM Working Group.

\section{REFERENCES}

1. Alazraki, M.P.; Hogan, J.A.; Levri, J.A.; Fisher, J.W. and A.E. Drysdale, A.E. (2002) "Solid Waste Management Requirements Definition for Advanced Life Support Missions - Results" $32^{\text {nd }}$ International Conference on Environmental Systems, SAE Technical Paper 2002-01-2478.

2. Hogan, J.A.; Alazraki, M.P.; Fisher, J.W. and J.A. Levri (2002) "Considerations in Selection of Solid Waste Management Approaches in Long-Duration Space Missions" $32^{\text {nd }}$ International Conference on Environmental Systems, SAE Technical Paper 200201-2476.
3. Levri, J.A.; Fisher, J.W.; Alazraki, M.P. and J.A. Hogan (2002) "Requirements Development issues for Advanced Life Support Systems: Solid Waste Management" $32^{\text {nd }}$ International Conference on Environmental Systems, SAE Technical Paper 200201-2479.

4. Levri, J.A.; Hogan, J.A.; Alazraki, M.P. (2001) Evaluation Criteria for Solid Waste Processing Research and Technology Development. $17^{\text {th }}$ Annual American Society for Gravitational and Space Biology Meeting, November 7-11, Alexandria, Virginia.

5. OBPR database, 2003: http://research.hq.nasa.gov/taskbook.cfm

6. SBIR database, 2003: http://sbir.asfc.nasa.gov/SBIR/front1.htm|

7. Tech-net database, 2003: http://technet.sba.gov/tech-net/search.html

\section{CONTACT}

Julie A. Levri

NASA Ames Research Center

Mail Stop 239-8

Moffett Field, CA 94035

(650) 604-6917 (voice)

(650) 604-1092 (fax)

Julie.A.Levri@nasa.gov

\section{DEFINITIONS, ACRONYMS, ABBREVIATIONS}

ALS: Advanced Life Support

OBPR: Office of Biological and Physical Research

OTIS: On-line Technology Information System

Pl: Principal Investigator

R\&TD: Research and Technology Development

SBIR: Small Business Innovative Research

SWM: Solid Waste Management

TIF: Technology Information Form

TRL: Technology Readiness Level 